\title{
Effects of curzerene and Smyrnium cordifolium Boiss. extract on addiction withdrawal syndrome in mice
}

\author{
Pari Nazari $^{{ }^{*} \oplus}$, Parichehreh Yaghmaei ${ }^{1}$, Alireza Rangin ${ }^{2}$, Naser Abbasi ${ }^{3}$ \\ ${ }^{1}$ Department of Biology, Science and Research Branch, Islamic Azad University, Tehran, Iran \\ ${ }^{2}$ Department of Biology, Ilam Branch, Islamic Azad University, Ilam , Iran \\ ${ }^{3}$ Department of Pharmacology, Ilam University of Medical Sciences, Ilam, Iran
}

\section{AR T I C L E IN F O}

Article Type:

Original Article

\section{Article History:}

Received: 5 March 2018

Accepted: 2 September 2018

\section{Keywords:}

Addiction

Curzerene

Mice

Smyrnium cordifolium

Withdrawal syndrome

\begin{abstract}
A B S T R A C T
Introduction: The purpose of this study was evaluating the effect of Smyrnium cordifolium extract (SCE) and curzerene (Cur) on withdrawal syndrome in mice compared with clonidine. Methods: High-performance liquid chromatography (HPLC) was used to determine the active ingredients of S. cordifolium. To evaluate the effects of SCE and Cur, 64 mice were divided into 8 equal groups. Groups 1, 2 and 3 were treated $\operatorname{Cur}(0.03,0.06,0.12 \mathrm{mg} / \mathrm{kg}$, respectively). Groups 4,5 and 6 were treated with SCE $(100,200,300 \mathrm{mg} / \mathrm{kg}$, respectively). The seventh group received just morphine. Group 8 received morphine and clonidine $(0.2 \mathrm{mg} / \mathrm{kg})$.

Results: The results of this study showed that Cur was the most important ingredient in the extract of the plant, and the hydroalcoholic extract yield of S. cordifolium was $17.55 \%(\mathrm{w} / \mathrm{w})$. The dose of $100 \mathrm{mg} / \mathrm{kg}$ of extract (SCE100) and $0.03 \mathrm{mg} / \mathrm{kg}$ curzerene (Cur1) $(P<0.05)$, dose of $200 \mathrm{mg} / \mathrm{kg}$ of extract (SCE200) and dose of $0.06 \mathrm{mg} / \mathrm{kg}$ curzerene (Cur2), $(P<0.01)$, dose of 300 $\mathrm{mg} / \mathrm{kg}$ of extract $(\mathrm{SCE} 300)$ and dose of $0.12 \mathrm{mg} / \mathrm{kg}$ of curzerene $(\mathrm{Cur} 3)(P<0.001)$ decreased the symptoms compared to clonidine. Doses higher than $300 \mathrm{mg} / \mathrm{kg}$ of extract and $0.12 \mathrm{mg} /$ $\mathrm{kg}$ of Cur had fatal effects. All doses of SCE and Cur in comparison with the control group at significant level $(P<0.001)$ reduced the number of jumping, rearing and teeth chattering in morphine-dependent mice.

Conclusion: The findings suggest that SCE and Cur are capable of reducing the symptoms of withdrawal syndrome and their effectiveness may be more than clonidine in reducing the addiction withdrawal syndrome, which may have human therapeutic potential.
\end{abstract}

Implication for health policy/practice/research/medical education:

Curzerene (Cur) is the active ingredient of Smyrnium cordifolium extract both of which are capable of reducing the symptoms of withdrawal syndrome and might be beneficial for addicted individuals

Please cite this paper as: Nazari P, Yaghmaei P, Rangin A, Abbasi N. Effects of curzerene and Smyrnium cordifolium Boiss. extract on addiction withdrawal syndrome in mice. J Herbmed Pharmacol. 2018;7(4):280-286. doi: 10.15171/jhp.2018.42.

\section{Introduction}

Opioids are the most effective medications to relieve pain, depression, anxiety and withdrawal syndrome (1). Addiction and abuse of opioids are of the most important economic and social problems in the world (2). Longterm and repeated administration of opioids lead to tolerance and dependence and discontinuation of these substances causes signs such as pain, anxiety, aggression and withdrawal syndrome.

Many studies have shown that the use of some medicinal plants can reduce the symptoms of drug discontinuation.
In traditional medicine, many herbs such as Salvia limbata, Lavandula officinalis and Passiflora incarnata are used for their analgesic and hypnagogic effects (2). Also, Coriandrum sativum with narcolepsy and antianxiety effects is used in traditional medicine (3). In traditional Iranian medicine, Smyrnium cordifolium is used to treat anxiety and insomnia. There are limited reports regarding the analysis of $S$. cordifolium extract (SCE). In a study, by GC/MS, S. cordifolium essential oil was characterized by a high content of sesquiterpenes, most of them oxygenated sesquiterpenes with curzerene (16.9\%) and curzerenone 
(33.8\%) as major constituent (4). According to some studies of the mechanisms involved in opioid tolerance and dependence, neurotransmitter systems such as nitric oxide (5), glutamate (6) dopamine (7), and receptors of stimulatory amino acids especially the glutamate receptors (NMDA) were of great importance. The role of NMDA has been proven in the opioid synaptic shaping process $(8,9)$.

The genus Smyrnium is represented in the flora of Iran by only S. cordifolium Boiss species (Avendol), which is a biennial herb and widely distributed in the Zagrose mountains at an altitude of 1400-2000 $\mathrm{m}$ in the west and northwest of Iran. This plant has many nutritional and medicinal uses (10).

In traditional medicine of Iran, S. cordifolium is used to treat anxiety, pain, insomnia and withdrawal syndrome. A number of medicinal properties, e.g. diuretic, restorative and counteracting renal calculus have been described for all parts of the plant. Additionally, the fleshy stems of the plant are used as vegetables (4). The purpose of this study was to investigate the effects of SCE and curzerene (Cur) on withdrawal syndrome in mice compared with clonidine.

\section{Materials and Methods \\ Extraction}

The aerial parts of S. cordifolium used for the present study were collected by the authors during the flowering stage between February and March, 2017 from the Ghalajah Mountains of Ilam province in West of Iran. A voucher specimen of the collection was identified by Dr. Attar F. (Tehran University, Biology department, Iran) and deposited at the Department of Biology, Ilam Azad University, Iran (herbarium number IAU-9408). The aerial parts of the plant were dried in shade for a week and exposed to airflow at room temperature, then powdered with an electric mill. The plant extract was prepared by Soxhlet extraction method and powered. Each $15 \mathrm{~g}$ of powder was crushed into a thimble paper and extracted with $250 \mathrm{~mL}$ of $70 \%$ ethanol. The process of extraction continued until the solvent in siphon tube of the extractor became colorless (about 48 hours). In order to evaporate excessive solvent, the sample was then concentrated in a rotary vacuum distiller under negative pressure at $50^{\circ} \mathrm{C}$. The extract was incubated at $30-40^{\circ} \mathrm{C}$ until the solvent was completely isolated from the extract and powdered. The powder was preserved in sterile bottles at $-20^{\circ} \mathrm{C}$ until use (11).

Extract Analysis and Determination of Active Component by HPLC

High performance liquid chromatography (HPLC) was used to determine the Cur of $S$. cordifolium in comparison to standard Cur (ChemFaces Co., No: 17910-09-7). The HPLC system was Knauer (model 1000), consisted of a variable wavelength UV detector (model 2800), used at a wavelength of $230 \mathrm{~nm}$ with the outputs recorded and analyzed using a compatible software (ChromGate, Knauer), Nova-Pak C18 Column, 60A, $4 \mu \mathrm{m}, 4.6 \mathrm{~mm}$ X150 mm [WAT044375]. The mobile phase consisted of acetone, ethanol and acetonitrile solvents. The volume of a single injection was $1 \mu \mathrm{L}$. After each injection, the column was equilibrated for 15 minutes. The stock solutions of 5 standards were made at concentration of $1 \mathrm{mM}$ in a final volume of $10 \mathrm{~mL}$ of ethanol. In order to plot the calibration curve, working solutions of mixed standards at the concentrations of $3.1,6.2,12.5,25$ and $50 \mu \mathrm{M}$ were made by dilution of stock solution in volumetric flasks with the mobile phase. Then the standards were injected into the HPLC (12).

Animals

Sixty-four adult male mice (25-30 g) obtained from the Pasteur Institute (Tehran, Iran) were divided into 8 groups, each group consisting of 8 numbers. The animals were individually housed in eight ones per cage with a $12 / 12$ hours light/dark cycle and having free access to food and water. All experiments were performed in accordance with the Guiding Principles for Care and Use of Laboratory Animals of the Faculty of Medicine, Ilam University.

Drugs

Morphine and naloxone ampoules, and clonidine hydrochloride tablets were obtained from Tolid Daru Co, Tehran-Iran, and Cur from ChemFaces Co.

Development of addiction to morphine in mice The mice were injected subcutaneously with morphine twice daily for 7 days. The dose of morphine on days 1 and 2 was $2.5 \mathrm{mg} / \mathrm{kg}$; this dose was doubled every day to reach about $40 \mathrm{mg} / \mathrm{kg}$ on day 6 . On day seven, the mice received the last injection of morphine, $50 \mathrm{mg} / \mathrm{kg}$ (11).

Study of morphine addiction signs in mice

Mice of all groups received $3 \mathrm{mg} / \mathrm{kg}$ (i.p.) naloxone 4 hours after the last injection of morphine on day 7 of morphine treatment. Immediately each mouse was placed in a transparent cylinder (30 cm height, $20 \mathrm{~cm}$ in diameter) to observe the frequency of withdrawal manifestations (jumping, teeth chattering, rearing) for 30 minutes (11).

Simultaneous effect of morphine and Curzerene on withdrawal syndrome in mouse

Groups 1 (Cur1), 2 (Cur2), and 3 (Cur3) were treated intraperitoneally with different doses of Cur $(0.03,0.06$, $0.12 \mathrm{mg} / \mathrm{kg}$, respectively) and morphine.

Effect of co-administration of SCE and morphine on addiction withdrawal syndrome in mice Groups fourth (E100), fifth (E200) and sixth (E300), were 
treated with different doses of SCE $(100,200,300 \mathrm{mg} / \mathrm{kg}$, by gavage, respectively) and morphine.

Effect of co-administration of clonidine hydrochloride and morphine on the development of morphine dependence and expression of withdrawal syndrome

In group 7 clonidine hydrochloride (CLO, $0.2 \mathrm{mg} / \mathrm{kg}$, i.p.) was administered concurrently with morphine, twice daily for 6 days; and on day 7 they were injected the last dose of clonidine with morphine concurrently 4 hours before the naloxone challenge. The effect of Clonidine on the attenuation of morphine dependence was assessed by comparing the frequency of the behavioral withdrawal signs of animals in group 7 and also the ability of SCE and Cur in attenuation of morphine dependence versus clonidine was assessed by comparing groups $1,2,3,4,5$ and 6 (13). The mice in group 8 received just morphine as positive control group.

Statistical analysis

Analysis of the data was done by SPSS 19 and Excel 2015 software. Statistical analysis was performed to compare withdrawal syndrome behavioral manifestations, using one-way analysis of variance (ANOVA) and $t$ test analysis for the different groups. The data were represented as mean \pm SEM. The level of significance was set at $P<0.05$.

\section{Results}

Yields of SCE were obtained as being $17.55 \%(\mathrm{w} / \mathrm{w})$. The extract analysis was performed to confirm the passive value of the HPLC device on the Nova-Pak C18 column (60^, $4 \mu \mathrm{m}, 150 \mathrm{X} 4.6 \mathrm{~mm}$ ) and UV detector using a mobile phase including acetone, ethanol and acetonitrile solvents. In order to plot the calibration curve (Figure 1), for quantitative measurements of Cur, concentrations of 3.1, $6.2,12.5,25$ and $50 \mu \mathrm{M}$ were prepared from Cur standard and after filtration, each one injected three times into HPLC apparatus. The area under the curve was plotted

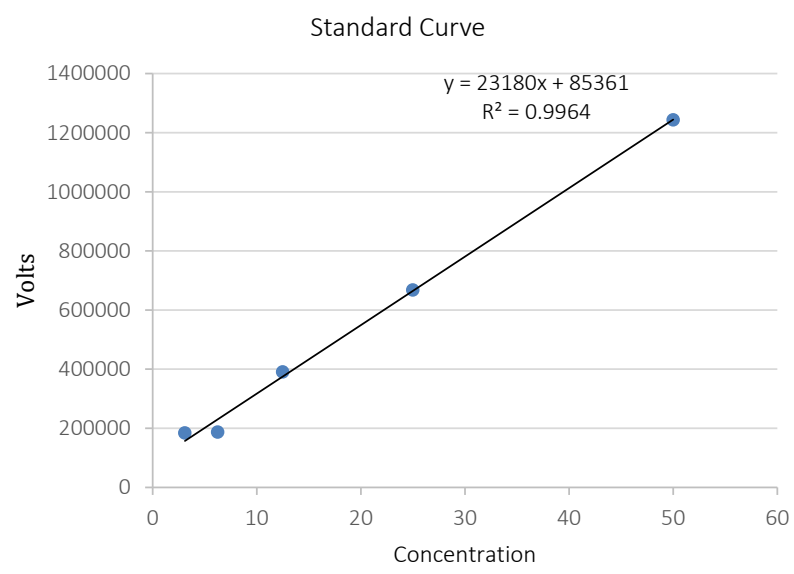

Figure 1. Calibration curve of Cur at concentrations of $3.1,6.2,12.5$, 25 and $50 \mu \mathrm{m}$ against the injection volume. The regression line and standard correlation coefficient of corrosion coefficient were calculated. The Cur output of the standard Cur medium appeared at a mean retention time of 8.183 minutes.

The regression line equation was defined as $y=23180 x+85361$. The correlation coefficient of Cur standard $\left(r^{2}\right)$ was $r^{2}=0.9964$ between the absorbance value at $230 \mathrm{~nm}$ wavelength from the standard curve (Figure 1 ), which by placing the surface area values below the curve obtained for Cur in the equation of regression line, the value $\mathrm{x}$, which is the same concentration of the SCE sample, was determined to be $6.95 \mu \mathrm{mol}$.

In the curve obtained from 3 times injection of SCE, the average peptide inhibition time of the extract was 7.717 minutes (Figure 2). The preceding and subsequent peaks correspond to the peak of the solvents at about the retention time. The HPLC results of the extract showed that Cur had the highest amount of its constituent material, as shown in Figure 2.

Repeated administration of morphine produced physical dependence as assessed by a characteristic set of behavioral responses including teeth chattering, jumping and rearing, following naloxone challenge. Repeated co-administration of SCE with morphine decreased significantly the frequencies of the signs of withdrawal syndrome compared with frequencies of withdrawal manifestations of morphine-dependent mice treated with clonidine. As shown in Figures 3 and 4, naloxone induced a highly significant increase in the mean frequency of rearing, teeth chattering, jumping in dependent mice treated with Cur and SCE compared with the clonidine and the control groups.

Figure 3 clearly shows that chronic morphine injection on the mean number of jumping during morphine withdrawal in Cur1 (mean of jump 22.75) significantly decreased the level $(P<0.05)$. Cur 2 significantly decreased the level $(P<0.01)$ compared to the clonidine group. In the Cur3 group (mean jump of 15.75), there was a significant decrease $(P<0.001)$ compared to the clonidine group. However, the mean number of jumps in these groups was significantly lower than the control (mean of jump 40.5) group. As shown in Figure 3, increasing the dose of

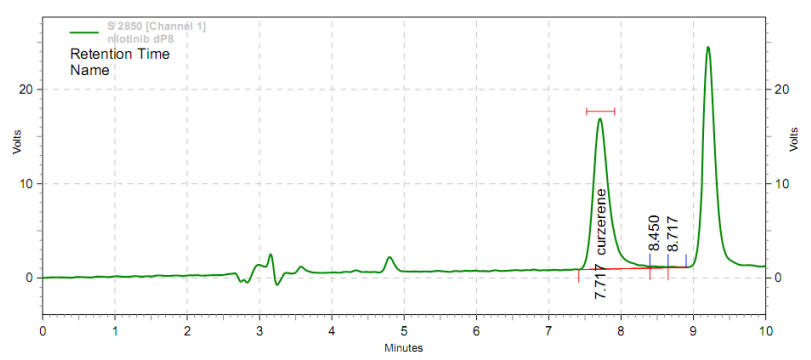

Figure 2. Curve obtained from injection of SCE obtained by HPLC analysis 


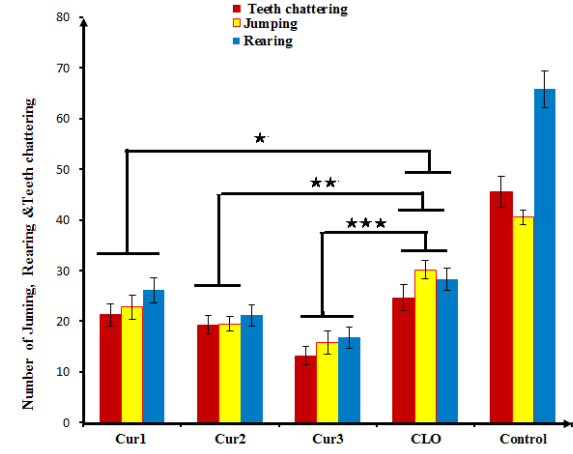

Figure 3. Mean of the jumping, rearing and teeth chattering Cur1: The group which received Cur $(0.03 \mathrm{mg} / \mathrm{kg})$ and morphine, Cur2: The group which received Cur $(0.06 \mathrm{mg} / \mathrm{kg})$ and morphine Cur3: The group which received Cur $(0.12 \mathrm{mg} / \mathrm{kg})$ and morphine, CLO: The group which received clonidine $(0.2 \mathrm{mg} / \mathrm{kg})$ and morphine, Control: The recipient received just morphine. Each column represents the mean \pm SEM $(n=8)$. ${ }^{*} P<0.05$, ${ }^{* *} P<0.01$, and ${ }^{* * *} P<0.001$.

Cur decreased significantly the frequency of the signs of withdrawal syndrome (group Cur1 compared with Cur2 and group Cur2 compared with Cur3).

Similarly, statistical analysis showed that chronic morphine injection during morphine withdrawal in Cur1, Cur2 and Cur3 groups significantly decreased the number of rearing compared to the clonidine group.

Also, Figure 3 distinctly shows that chronic morphine injection reduced the mean number of teeth chattering during morphine withdrawal in Cur1, Cur2 and Cur3 groups compared to the clonidine group. However, the mean number of jumps in all groups was significantly lower than the control (mean of teeth chattering 45.5) group $(P<0.001)$. One disadvantage was detected at a dose of $0.12 \mathrm{mg} / \mathrm{kg}$ Cur which increased the mortality rate of mice in co-administration with morphine.

Results showed that orally administration of SCE by an NG tube at concentrations of 100, 200 and $300 \mathrm{mg} / \mathrm{kg}$ significantly reduced the number of jumping episodes in morphine-dependent mice. Clonidine, as a reference drug, caused a significantly reduced number of jumping, rearing and teeth chattering episodes.

Figure 4 obviously shows that chronic morphine injection on the mean number of jumping during morphine withdrawal in SCE100 (mean of jump 20.38) significantly decreased the level $(P<0.05)$. SCE200 (mean of jump 16.88) significantly decreased the level $(P<0.01)$ compared to the clonidine group. In the SCE300 group (mean jump of 8.13), there was a significant decrease $(P<0.001)$ compared to the clonidine group. The mean number of jumps in these groups was significantly lower than the control group.

Statistical analysis clearly showed that chronic morphine injection reduced the mean number of teeth chattering during morphine withdrawal in the SCE100 (mean of teeth chattering 17) $(P<0.05)$, SCE200 (mean of teeth

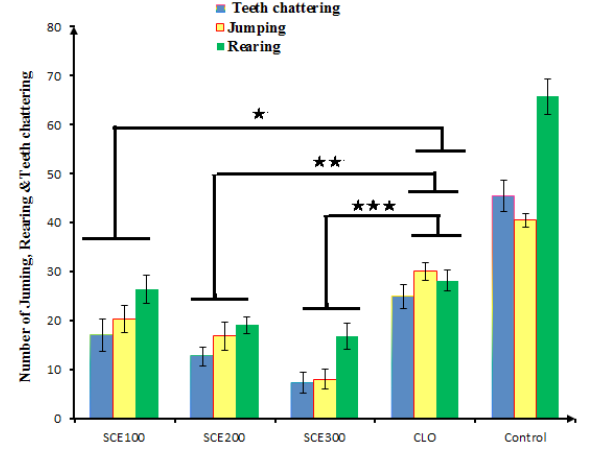

Figure 4. Mean of the jumping, rearing and teeth chattering. SCE100: The group which received SCE $(100 \mathrm{mg} / \mathrm{kg})$ and morphine), SCE2: The group which received SCE $(200 \mathrm{mg} / \mathrm{kg})$ and morphine, SCE3: The group which received SCE $(300 \mathrm{mg} /$ $\mathrm{kg})$ and morphine, CLO: The group which received clonidine $(0.2$ $\mathrm{mg} / \mathrm{kg}$ ) and morphine, Control: The recipients that just received morphine. Each column represents the mean $\pm \operatorname{SEM}(n=8)$. * $P<0.05,{ }^{* *} P<0.01$, and ${ }^{* * *} P<0.001$.

chattering 12.75) $(P<0.01)$ and SCE300 (mean of teeth chattering 7.38) $(P<0.001)$ compared to clonidine and control groups. Doses higher than $300 \mathrm{mg} / \mathrm{kg}$ of extract and $0.12 \mathrm{mg} / \mathrm{kg}$ of Cur had fatal effects.

The mean number of rearing was significantly decreased in SCE100 $(P<0.05)$, SCE200 $(P<0.01)$ and SCE300 $(P<0.001)$ groups in comparison to the clonidine group when morphine was discontinued (Figure 4).

\section{Discussion}

This study showed that the main and effective component of SCE is one of the sesquiterpenes (a class of C15 substance derived from 3 isoprene units) called Cur. This study showed that the SCE and the effective combination of the extract of this plant could be useful in reducing the symptoms of withdrawal syndrome.

Terpenoids and sesquiterpenes have the most diversity among plant compounds (14). So far, more than 40000 compounds have been identified with molecular structures and diverse biological activities. Most of them are produced by secondary metabolism (15). Phytochemical studies of S. cordifolium caused the identification of some sesquiterpenes, especially curzerenone and Cur, which had the highest amounts in its essential oil (16). Also, in $S$. perfoliatum plant, sesquiterpene germacrene, isopimarol, $D$-germacrone and $\beta$-pinene compounds have been reported (17). In another study, Maggi et al identified the compounds of isofuranogermacrene, Cur, germacrone, D-germacrene, isofuranodiene, $\beta$-phyllocladanal, $\alpha$-pinene and $\beta$-pinene, from S. olusatrum (18). Amiri et al indicate that the major part of the essential oil of S. cordifolium was sesquiterpene compounds, of which Cur $(16.9 \%)$ and curzerenone $(33.8 \%)$ had the highest amounts, and the other compounds of this plant included D-germacrone $13 \%$ and isopimarol with $10.9 \%$ (4) that are consistent with the results of our research. Also, 
previous studies with GC-MS and GC-FID showed that $S$. cordifolium contained more than 16 substances that Cur with $65.26 \%$ of the plant extract composition and $\delta$-cadinene with $14.3 \%, \gamma$-elemene with $5.15 \%$, curzerenone with $2.43 \%$, and germacrone with $2.18 \%$ were other components of S. cordifolium (19).

Smyrnium cordifolium is used in traditional medicine by Iran to treat inflammatory, anxiety and insomnia. Although the anticonvulsant properties of $S$. cordifolium essential oil have been investigated (20), it is the first time that the reducing signs of addiction withdrawal effects of SCE and Cur were studied.

The results of this study indicate that the major part of the SCE contains Cur. Recently, the pharmacotherapy of opioid tolerance and addiction has drawn intensive interest. The results of this study showed that chronic administration of morphine for 7 days caused dependence and tolerance to the effects of this substance. These findings are consistent with the Zarrindast study (7). The results showed that treatment with different doses of SCE during the 7-day program with morphine, reduced the symptoms of addictive drug withdrawal syndrome in morphine-dependent mice. Terpenoids, sesquiterpenes and herbs containing these compounds exhibit antinociceptive, anti-anxiety and sedative activities (21). Therefore, Cur and the compounds present in the SCE may be part of the anti-nociceptive and decreasing effects of withdrawal syndrome through various mechanisms such as GABAergic, opioidergic and serotonergic mechanisms. There are opioid receptors within the CNS as well as throughout the peripheral tissues. The $\mu, \kappa$ and $\delta$ opioid receptors are related to pain and addiction. The opioid receptors are attached to the G-protein and affect the opening of the ion channels, intracellular transmissions and protein phosphorylation. The general antagonist of these receptors (naloxone) is capable of inhibiting the analgesic effects of opioid receptors and preventing analgesia. Naloxone inhibits the effectiveness of analgesic drugs such as morphine. This drug tends to have the $\mu$ opioid receptor in the central nervous system, but less opioid receptors $\kappa$ and $\delta$ (22). This may happen for dependence effects of morphine.

Based on studies conducted with the activation of these receptors, calcium entry into the cell increases. Obviously, increasing intracellular calcium concentrations can activate some types of calcium-dependent secondary propagandists. This leads to several effects, such as facilitating the activity of $\mathrm{Ca}^{2+} /$ calmodulin-dependent protein kinase II (CaMkII) (23), regulating positive feedback activity of protein kinase $\mathrm{C}$ (24), the activation of nitric oxide synthase (NOS), and finally, the production of nitric oxide (NO) (25). Nitric oxide is a nerve modulator derived from the L-arginine nitric oxide synthase enzyme. The NOS enzyme is activated by calcium-calmodulin, protein kinase II (CaMkII) (26). A lot of researches have suggested that $\mathrm{NO}$ is involved in inducing morphine tolerance and dependence. There is also evidence that $\mathrm{NO}$ can be co-administered with other neurotransmitter systems, such as the glutamatergic system and the NMDA receptor for its role $(27,28)$. Also, the research shows that there is a two-way relationship between the production of $\mathrm{NO}$ and the release of dopamine (29). It seems that the SCE with an effect on the CNS and PNS might be effective in the treatment of anxiety, pain, insomnia, and reduce the symptoms of its addiction withdrawal syndrome. The present study showed that injection of Cur and SCE had a significant decrease in the number of jumping, teeth chattering and rearing in morphine-dependent mice in comparison to the Control and Clonidine groups. These results are, in part, consistent with the results of other studies (19). Creating a rapid dependence restricts the usefulness of morphine in long-term treatment, but Cur and SCE are thought to be good agonists for the replacement of morphine.

Central serotonergic nerves are of the neurological systems involved in opioid dependence. On the other hand, sesquiterpenes such as Cur may have analgesic properties, and as an activator of the CNS, by stimulating the anxiety interventionist system, are effective on the surface of the GABA (30). Hence, it is possible that SCE can reduce the symptoms of discontinuation of morphine. Previous studies have shown that discontinuation of morphine leads to a significant reduction in serotonin in several CNS regions, including dorsal raphe nuclei. Also, the electrical stimulation of the dorsal raphe nucleus and enhances the release of serotonin. Serotonin in the hypothalamus leads to stimulation of release enkephalins and decreases the withdrawal symptoms. Therefore, it seems that serotonin is one of the factors involved in physiological changes and behaviors involved in opiate withdrawal (31). Research has shown that terpenoids also have analgesic effects through interference with the opioid system (32). Probably effective compounds such as Cur and SCE have the ability to stimulate the serotonergic system. Therefore, according to the above, it can be justified that the SCE may reduce withdrawal symptoms by releasing serotonin.

The administration of naloxone as an opioid receptor antagonist has reduced the analgesic effect of the SCE and it has been stated that the analgesic effect of the SCE is probably related to the effect of the opioid system. Therefore, with chronic morphine administration, possibly endogenous opioids, including Met-enkephalin, are reduced. This reduction is apparent when naloxone is injected and the SCE showed to be able to prevent these symptoms. It can be argued that some of the SCE compounds such as Cur, with opioid-like properties, reduces morphine withdrawal symptoms, which is consistent with previous studies $(33,34)$.

\section{Conclusion}

It appears that the compounds present in S. cordifolium 
extract such as Cur are capable of reducing the symptoms of withdrawal syndrome and their effectiveness may be more than clonidine. This may have human therapeutic potential.

\section{Acknowledgments}

The authors would like to appreciate the Ilam of laboratory of Islamic Azad University, Ilam, Iran, for their help.

\section{Authors' contributions}

NP and RA performed the data collection, design of the study, literature search, funding collection, data interpretation and manuscript preparation. YP and AN carried out statistical analysis, design of the study and literature search. The authors read and confirmed the publication of the manuscript.

\section{Ethical considerations}

All experimental procedures were conducted with the approval of the Ethics Committee of Islamic Azad University of Science and Research Branch of Tehran with an ethical code of 52734 .

\section{Funding/Support}

This research was financially supported by the Islamic Azad University of Science and Research Branch of Tehran with grant number 930542746 .

\section{References}

1. Christie MJ. Cellular neuroadaptations to chronic opioids: tolerance, withdrawal and addiction. Br J Pharmacol. 2008;154(2):384-96. doi: 10.1038/bjp.2008.100.

2. Abbasi Maleki S. Effect of ethanolic extract of Safflower on naloxone-induced morphine withdrawal signs in mice. Adv Herb Med. 2015;1(4):9-15.

3. Saghaei S, Abbasi Maleki S. Evaluation of the Effect of Coriandrum sativum L. Essentisal oil on Naloxone-Induced Jumping in Morphine-Dependent Mice. J Fasa Univ Med Sci. 2018;7(4):521-9.

4. Amiri H, Khavari-Nejad RA, Rustaiyan A. Chemical composition of essential oil and the study of secretory anatomy from Smyrnium cordifolium Boiss. Pajouhesh Sazandegi J. 2007;20(1):11-6.

5. Ozdemir E, Bagcivan I, Durmus N, Altun A, Gursoy S. The nitric oxide-cGMP signaling pathway plays a significant role in tolerance to the analgesic effect of morphine. Can J Physiol Pharmacol. 2011;89(2):89-95. doi: 10.1139/y10109.

6. Capone F, Adriani W, Shumilina M, Izykenova G, Granstrem O, Dambinova S, et al. Autoantibodies against opioid or glutamate receptors are associated with changes in morphine reward and physical dependence in mice. Psychopharmacology (Berl). 2008;197(4):535-48. doi: 10.1007/s00213-007-1062-y.

7. Zarrindast MR, Bahreini T, Adl M. Effect of imipramine on the expression and acquisition of morphine-induced conditioned place preference in mice. Pharmacol Biochem Behav. 2002;73(4):941-9.
8. Noda Y, Nabeshima T. Opiate physical dependence and N-methyl-D-aspartate receptors. Eur J Pharmacol. 2004;500(1-3):121-8. doi: 10.1016/j.ejphar.2004.07.017.

9. Kest B, Palmese CA, Hopkins E, Adler M, Juni A. Assessment of acute and chronic morphine dependence in male and female mice. Pharmacol Biochem Behav. 2001;70(1):149-56.

10. Zargari A. Iranian Medicinal Plants. Tehran: Tehran University Publications; 1997. (Persian).

11. Feily A, Abbasi N. The inhibitory effect of Hypericum perforatum extract on morphine withdrawal syndrome in rat and comparison with clonidine. Phytother Res. 2009;23(11):1549-52. doi: 10.1002/ptr.2807.

12. Cimpan G, Gocan S. Analysis of medicinal plants by HPLC: Recent approaches. J Liq Chromatogr Relat Technol. 2002;25(13-15):2225-92. doi: 10.1081/JLC-120014003.

13. Sahraei H, Faghih-Monzavi Z, Fatemi SM, Pashaei-Rad S, Salimi SH, Kamalinejad M. Effects of Papaver rhoeas extract on the acquisition and expression of morphineinduced behavioral sensitization in mice. Phytother Res. 2006;20(9):737-41. doi: 10.1002/ptr.1922.

14. Roberts SC. Production and engineering of terpenoids in plant cell culture. Nat Chem Biol. 2007;3(7):387-95. doi: 10.1038/nchembio.2007.8.

15. Withers ST, Keasling JD. Biosynthesis and engineering of isoprenoid small molecules. Appl Microbiol Biotechnol. 2007;73(5):980-90. doi: 10.1007/s00253-006-0593-1.

16. Ulubelen A, Goren N, Bohlmann F, Jakupovic J, Grenz M, Tanker N. Sesquiterpene lactones from Smyrnium cordifolium. Phytochemistry. 1985;24(6):1305-8. doi: 10.1016/S0031-9422(00)81121-8.

17. Molleken U, Sinnwell V, Kubeczka KH. The essential oil composition of fruits from Smyrnium perfoliatum. Phytochemistry. 1998;47(6):1079-83. doi: 10.1016/S00319422(98)80076-9.

18. Maggi F, Papa F, Giuliani C, Maleci Bini L, Venditti A, Bianco A, et al. Essential oil chemotypification and secretory structures of the neglected vegetable Smyrnium olusatrum L. (Apiaceae) growing in central Italy. Flavour Fragr J. 2015;30(2):139-59. doi: 10.1002/ffj.3221.

19. Abbasi N, Mohammadyari E, Asadollahi KH, Tahmasebi M, Ghobad A, Taherikalani M. Medicinal characteristics of Smyrnium cordifolium Boiss. plant extract in rats. J Med Plant Res. 2014;8(9):395-400. doi: 10.5897/JMPR2013.5237.

20. Abbasi N, Mohammadpour S, Karimi E, Aidy A, Karimi P, Azizi M, et al. Protective effects of Smyrnium cordifolium Boiss essential oil on pentylenetetrazol-induced seizures in mice: involvement of benzodiazepine and opioid antagonists. J Biol Regul Homeost Agents. 2017;31(3):6839.

21. Shahnouri M, Abouhosseini Tabari M, Araghi A. Neuropharmacological properties of farnesol in Murine model. Iran J Vet Res. 2016;17(4):259-64.

22. Lutz PE, Ayranci G, Chu-Sin-Chung P, Matifas A, Koebel P, Filliol D, et al. Distinct mu, delta, and kappa opioid receptor mechanisms underlie low sociability and depressive-like behaviors during heroin abstinence. Neuropsychopharmacology. 2014;39(11):2694-705. doi: 10.1038/npp.2014.126.

23. Takata T, Kimura J, Tsuchiya Y, Naito Y, Watanabe Y. 
Calcium/calmodulin-dependent protein kinases as potential targets of nitric oxide. Nitric Oxide. 2011;25(2):145-52. doi: 10.1016/j.niox.2011.01.004.

24. Mestek A, Hurley JH, Bye LS, Campbell AD, Chen Y, Tian $\mathrm{M}$, et al. The human mu opioid receptor: modulation of functional desensitization by calcium/calmodulindependent protein kinase and protein kinase C. J Neurosci. 1995;15(3 Pt 2):2396-406.

25. Heinzen EL, Pollack GM. Pharmacodynamics of morphine-induced neuronal nitric oxide production and antinociceptive tolerance development. Brain Res. 2004;1023(2):175-84. doi: 10.1016/j.brainres.2004.07.015.

26. Hoque KE, Indorkar RP, Sammut S, West AR. Impact of dopamine-glutamate interactions on striatal neuronal nitric oxide synthase activity. Psychopharmacology (Berl). 2010;207(4):571-81. doi: 10.1007/s00213-009-1687-0.

27. Hong JT, Kim HC, Kim HS, Lee YM, Oh KW. The role of nitric oxide on glutaminergic modulation of dopaminergic activation. Pharmacol Res. 2005;52(4):298-301. doi: 10.1016/j.phrs.2005.05.002.

28. Davis AM, Inturrisi CE. d-Methadone blocks morphine tolerance and N-methyl-D-aspartate-induced hyperalgesia. J Pharmacol Exp Ther. 1999;289(2):1048-53.

29. Kiss JP, Vizi ES. Nitric oxide: a novel link between synaptic and nonsynaptic transmission. Trends Neurosci. 2001;24(4):211-5

30. Assadi A, Zarrindast MR, Jouyban A, Samini M. Comparing of the effects of hypericin and synthetic antidepressants on the expression of morphine-induced conditioned place preference. Iran J Pharm Res. 2011;10(3):916-26.

31. Fereidoni $\mathrm{M}$, Etemadi L. Involvement of Opioidergic and Serotoninergic systems in the anti-nociceptive effect of Tanacetum parthenium. Physiol Pharmacol. 2008;12(2):115-20

32. Law PY, Loh HH, Wei LN. Insights into the receptor transcription and signaling: implications in opioid tolerance and dependence. Neuropharmacology. 2004;47 Suppl 1:300-11. doi: 10.1016/j.neuropharm.2004.07.013.

33. Quillinan N, Lau EK, Virk M, von Zastrow M, Williams JT. Recovery from mu-opioid receptor desensitization after chronic treatment with morphine and methadone. J Neurosci. 2011;31(12):4434-43. doi: 10.1523/ jneurosci.4874-10.2011.

34. Subhan F, Khan M, Ibrar M, Nazar-ul-Islam, Gilani A, Khan A. Effect of aqueous ethanol extract of Hypericum perforatum on naloxane-precipitated opium withdrawal syndrom. Iran J Pharm Res. 2004;3(Suppl 2):42-3. 